\title{
A. Vue d'ensemble des flux financiers et commerciaux entre la Suisse et les pays en développement
}

Gérard Perroulaz, Tanja Guggenbühl et Xavier Tschumi Canosa

\section{OpenEdition}

\section{Journals}

Édition électronique

URL : http://journals.openedition.org/aspd/225

DOI : 10.4000/aspd.225

ISSN : 1663-9669

Éditeur

Institut de hautes études internationales et du développement

\section{Édition imprimée}

Date de publication : 1 avril 2008

Pagination : 223-232

ISBN : 978-2-940415-01-4

ISSN : $1660-5934$

Référence électronique

Gérard Perroulaz, Tanja Guggenbühl et Xavier Tschumi Canosa, «A. Vue d'ensemble des flux

financiers et commerciaux entre la Suisse et les pays en développement », Annuaire suisse de politique de développement [En ligne], 27-1 | 2008, mis en ligne le 01 juillet 2009, consulté le 08 septembre 2020. URL : http://journals.openedition.org/aspd/225 ; DOI : https://doi.org/10.4000/aspd.225 


\section{A. Vue d'ensemble des flux financiers et commerciaux entre la Suisse et les pays en développement}

\section{A.1. Commentaires sur les chiffres des tableaux $A$}

Le tableau A.1 présente, pour la Suisse, une synthèse par catégorie de pays des flux d'aide publique au développement (APD) et autres apports du secteur public (AASP), d'aide privée délivrée par les ONG, des montants versés au titre de la Garantie contre les risques à l'exportation (GRE), des investissements directs à l'étranger ainsi que des importations et des exportations de biens durant l'année 2006. Il s'agit d'une synthèse ne concernant que les pays bénéficiaires d'aide publique au développement, selon la liste établie par le Comité d'aide au développement (CAD) de l'Organisation de coopération et de développement économiques (OCDE). Cette liste est reproduite à la fin du présent Annuaire.

Alors que les pays les moins avancés (PMA) ont reçu un cinquième de l'APD bilatérale de la Suisse et pratiquement deux cinquièmes de l'aide privée des ONG en 2006, ces pays ne sont que très marginalement la destination des flux d'investissements directs à l'étranger (IDE) de la Suisse et ne représentent qu'un pourcentage mineur de son commerce extérieur avec les pays bénéficiaires d'APD.

Dans la liste du CAD, les pays bénéficiaires d'APD hors PMA se divisent entre pays à faible revenu (disposant de moins de 825 dollars US par habitant en 2004) et pays à revenu intermédiaire (entre 826 et 3255 dollars US par habitant en 2004 pour la tranche inférieure et entre 3256 et 10065 dollars US par habitant en 2004 pour la tranche supérieure). Ces pays captent bien sûr une partie de l'APD et de l'aide privée des ONG de la Suisse - mais quasiment l'intégralité des investissements directs à l'étranger de la Suisse destinés aux pays bénéficiaires d'APD. En ce qui concerne le commerce extérieur de la Suisse avec ces pays en 2006, plus de quatre francs sur cinq concernent les pays à revenu intermédiaire, tant pour les importations que pour les exportations.

En chiffres absolus, il est intéressant de constater que, en 2006, le montant de l'APD et des autres apports du secteur public est près de huit fois moins important que celui des investissements directs à l'étranger de la Suisse vers les pays bénéficiaires d'APD. Si, pour les PMA, les flux d'APD et des AASP sont huit fois plus élevés que ceux d'IDE, c'est tout le contraire dans les autres pays bénéficiaires d'APD (hors PMA), pour qui l'APD et les AASP représentent moins d'un vingtième du montant des IDE.

Le commerce extérieur de la Suisse avec les pays bénéficiaires d'APD présente un solde commercial positif pour l'ensemble de ces pays, mais également pour chacune des catégories retenues par le CAD (PMA, pays à faible revenu et pays 
à revenu intermédiaire). Par «solde commercial positif», il faut comprendre un montant des exportations de la Suisse vers ces pays supérieur au montant des importations de la Suisse en provenance de ces pays. Le tableau A.2 montre que l'Afrique est le seul continent avec lequel la Suisse a un solde commercial négatif, en raison principalement du montant conséquent des importations de pétrole libyen et nigérian.

Le tableau A.3 présente encore un certain nombre de chiffres concernant les flux vers d'autres pays du Sud et de l'Est qui ne sont plus bénéficiaires d'APD au sens du CAD depuis 2005, mais qui apparaissaient dans des agrégats précédemment retenus par le CAD: il s'agit des pays qui étaient dits en transition, soit les pays de l'Europe centrale et orientale ainsi que les nouveaux Etats indépendants de l'ex-Union soviétique, et des pays dits «en développement plus avancés». Comme ces pays ne constituent plus une ou plusieurs catégories en soi, le tableau A.3 ne mentionne pas de totaux. Il est cependant intéressant de noter que le montant des exportations suisses en 2006 uniquement vers Hongkong a dépassé celui des exportations suisses vers l'ensemble des PMA et des pays à faible revenu. Pour comparaison encore, les exportations suisses vers l'Allemagne ont été dix fois supérieures en valeur à celles vers Hongkong. 


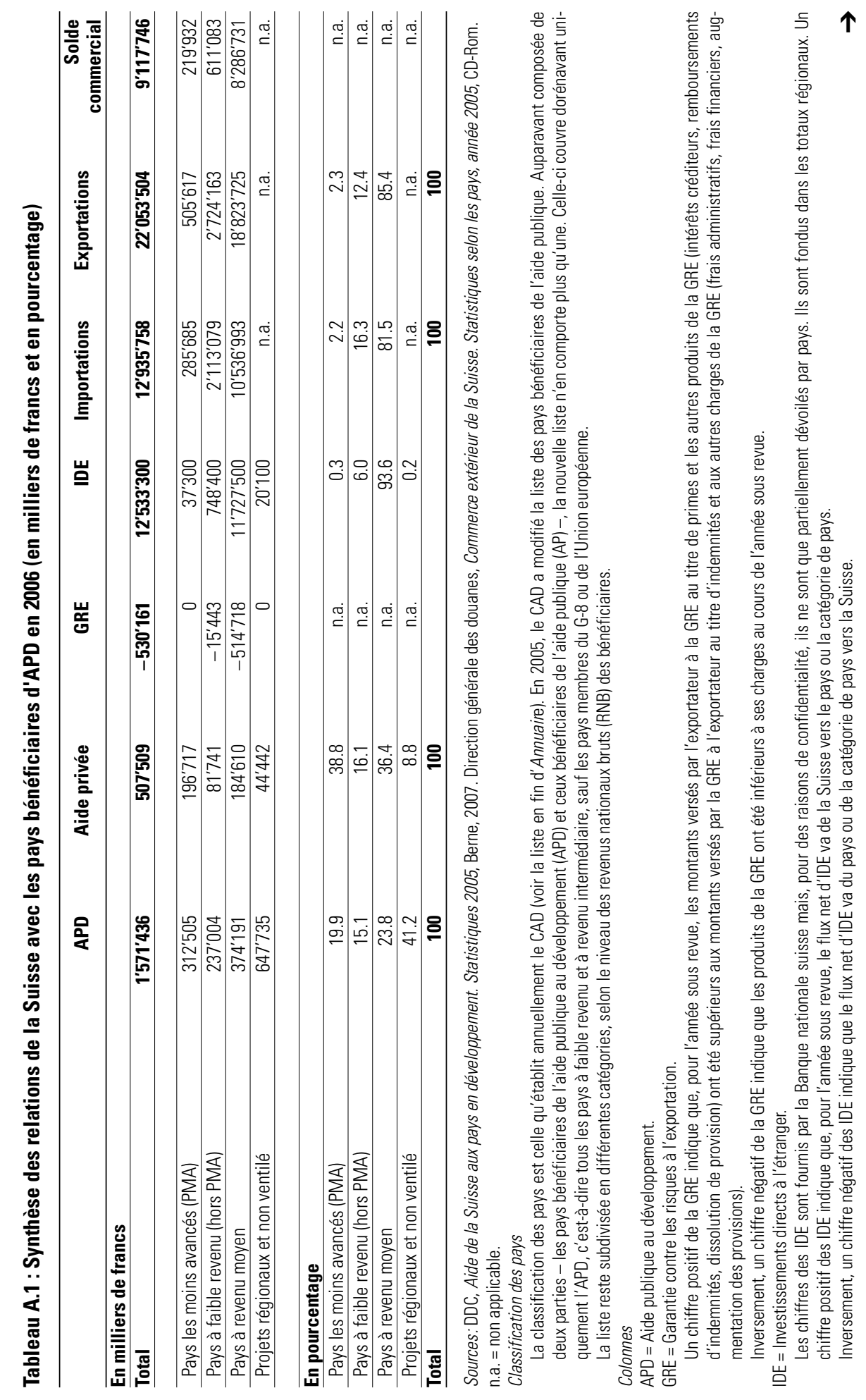




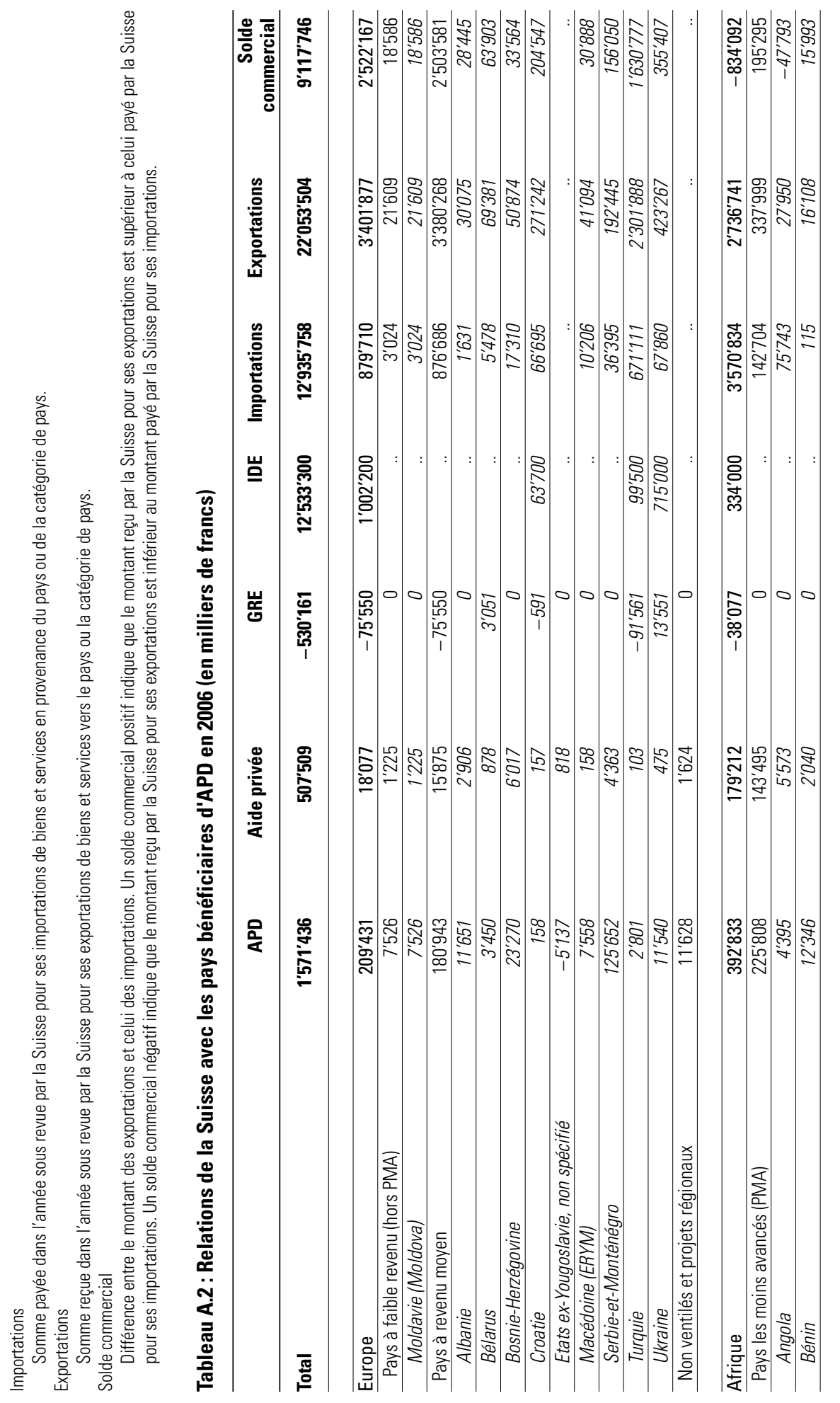




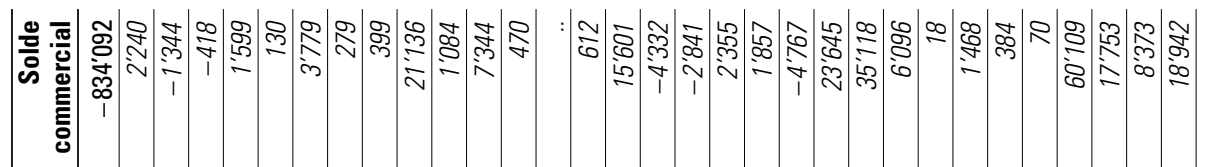

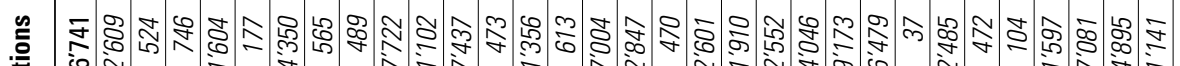

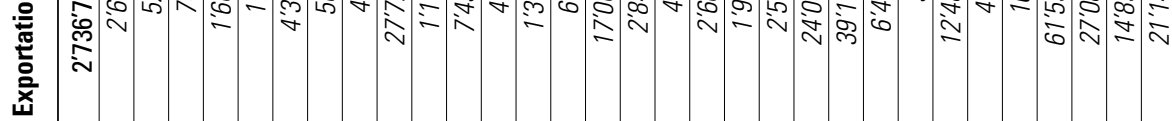

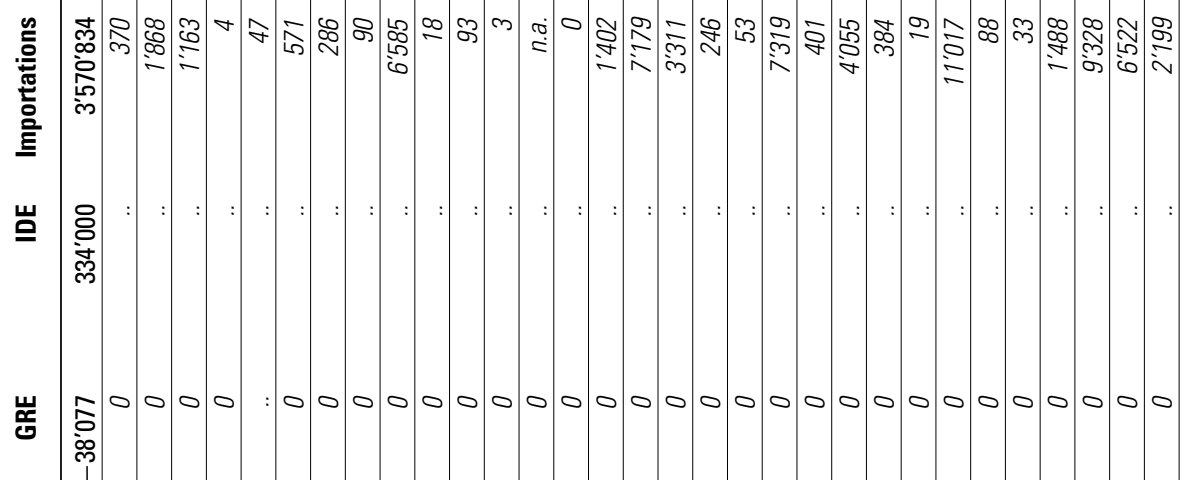

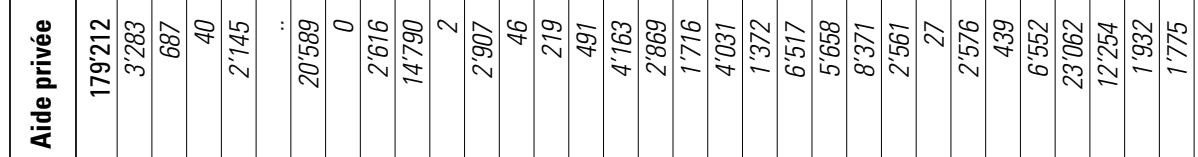

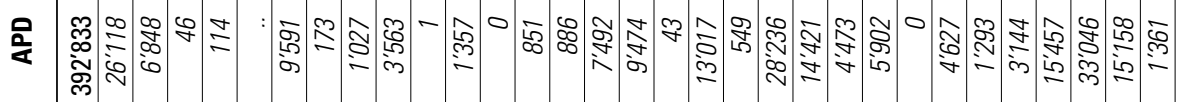

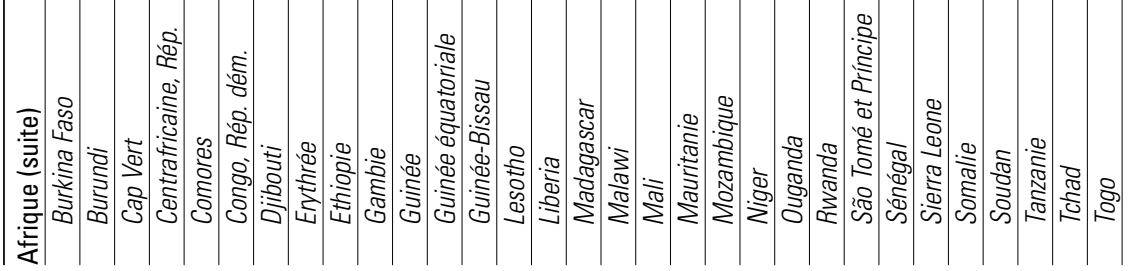




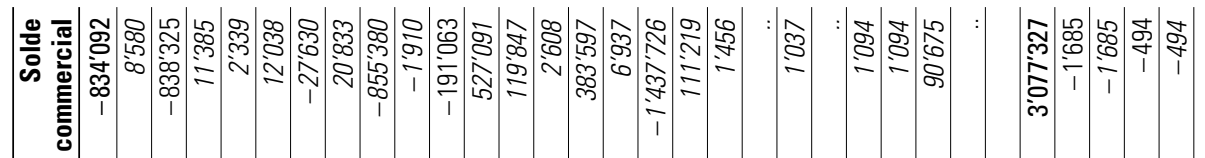

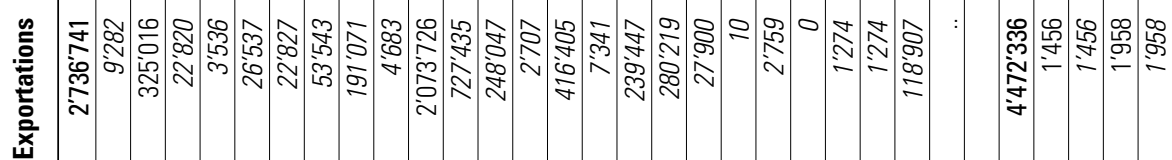

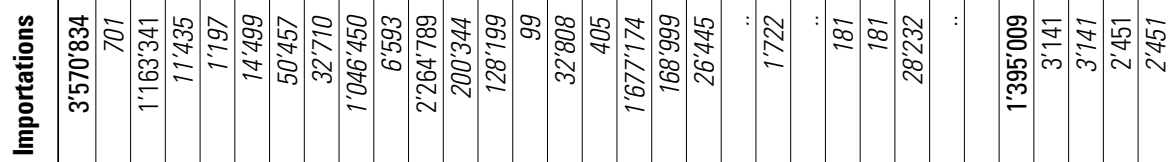

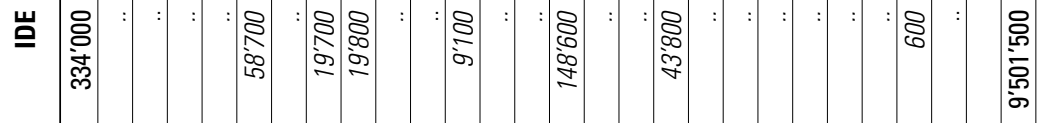

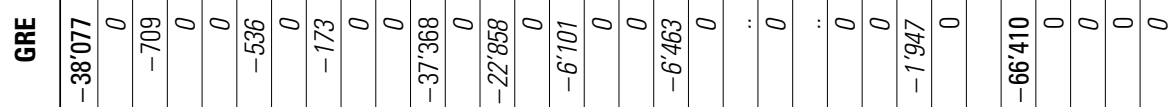

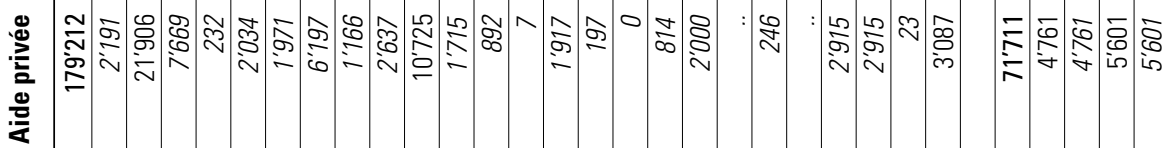

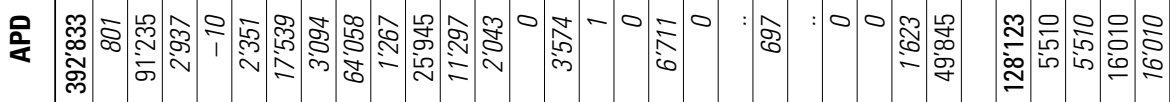

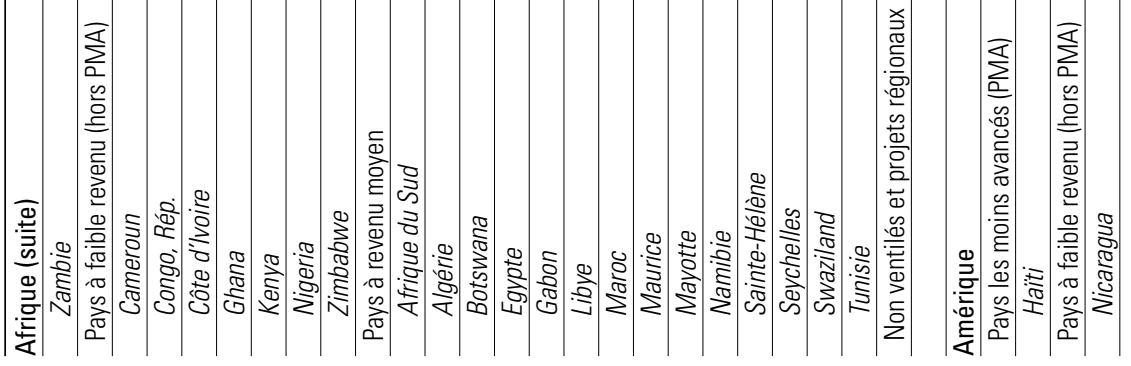




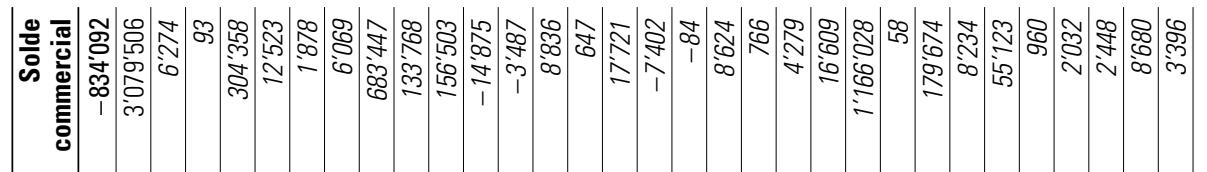

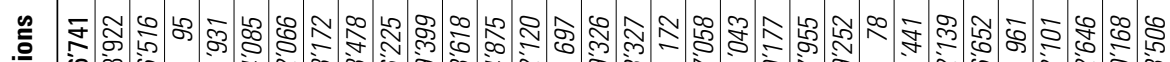

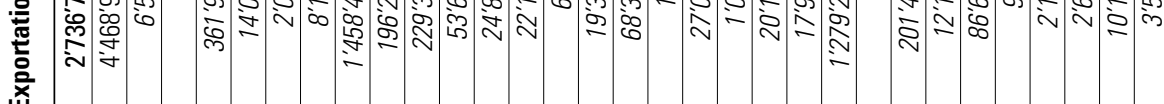

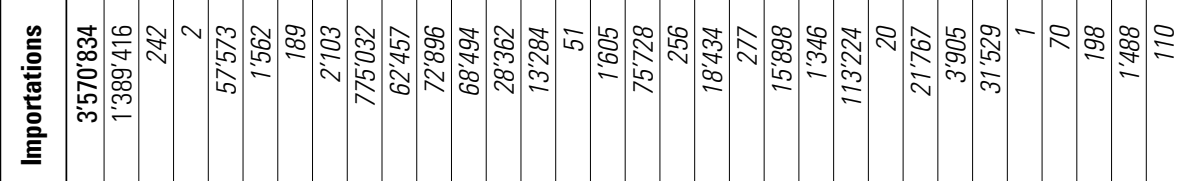

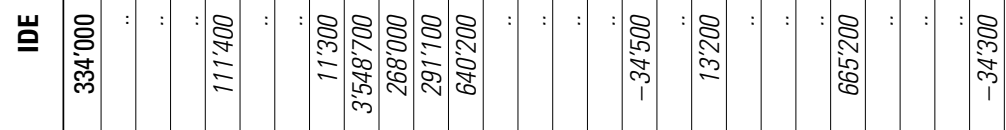

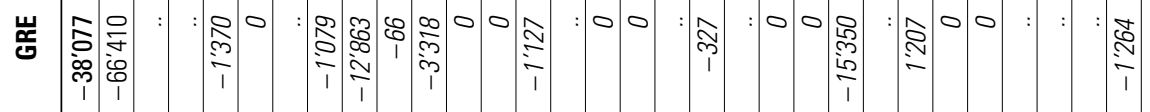

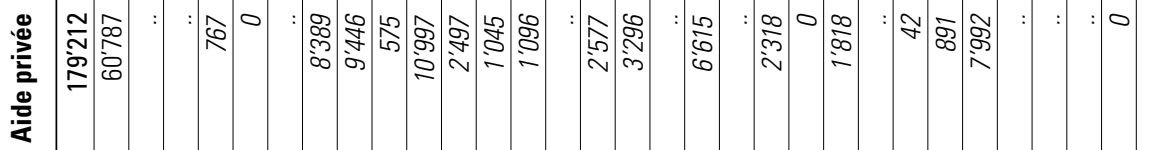

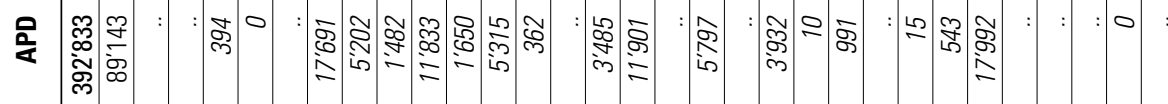

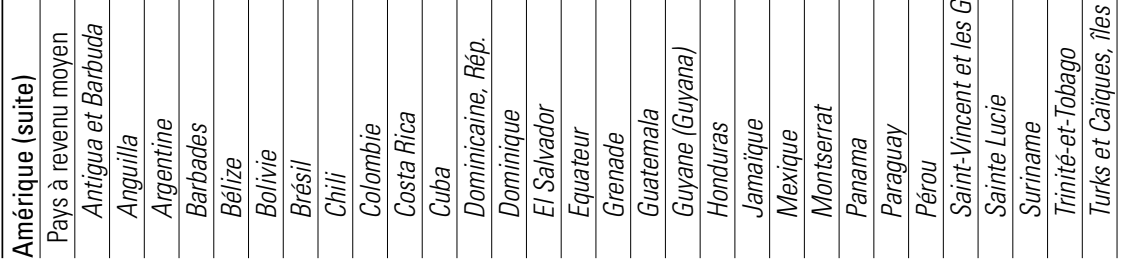




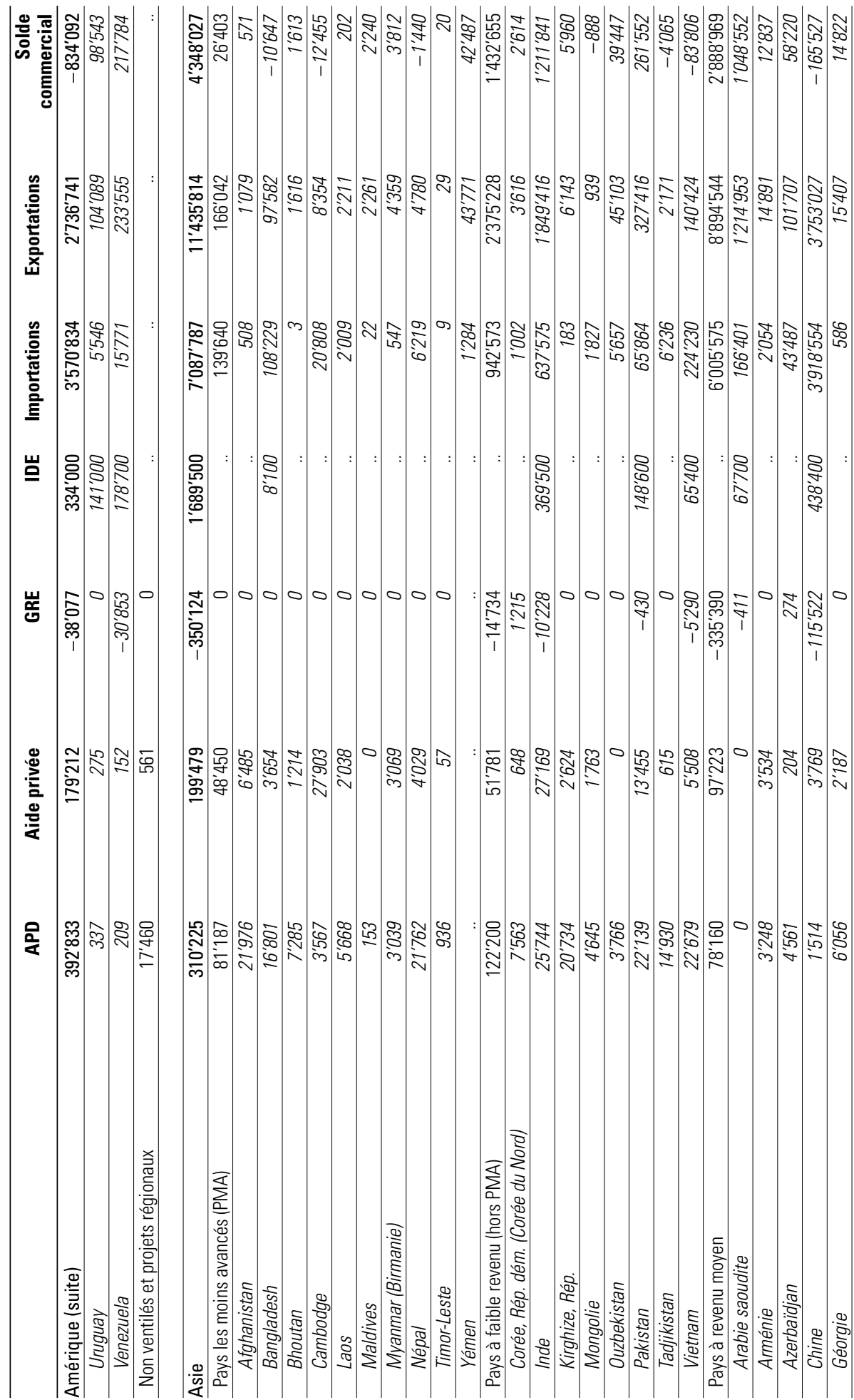




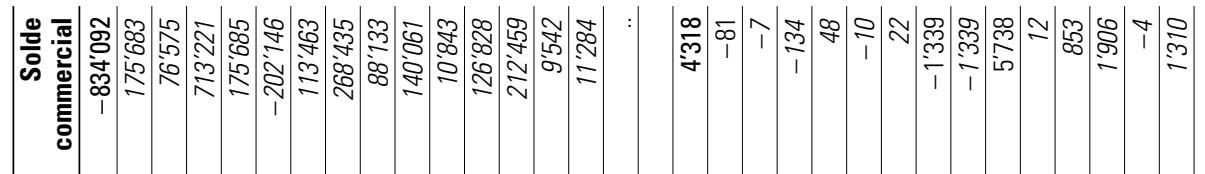

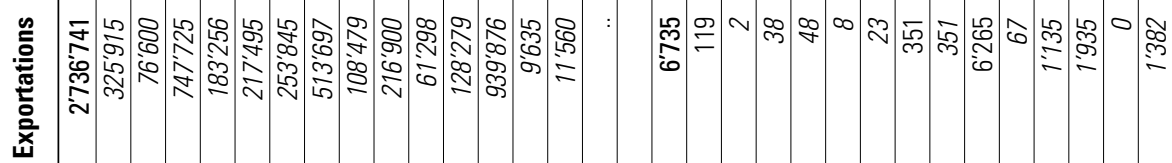

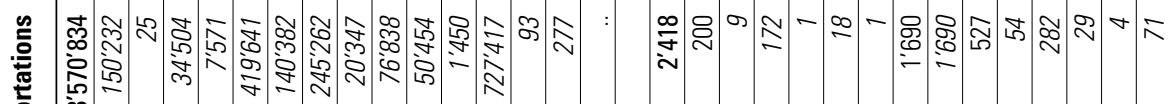

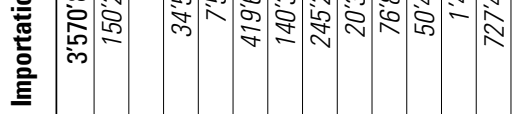

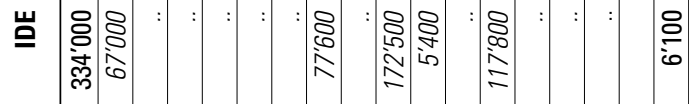

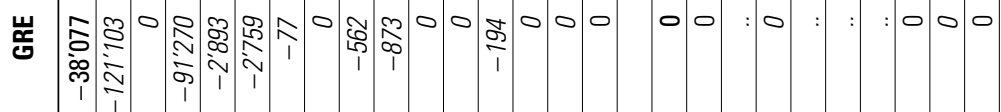

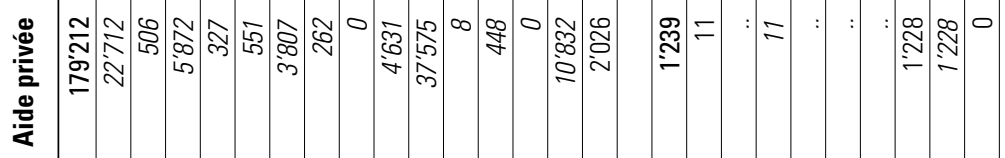

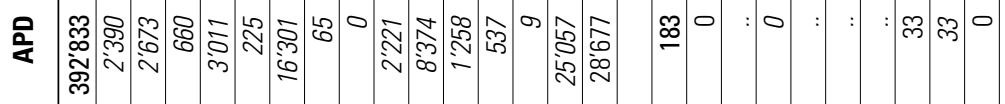

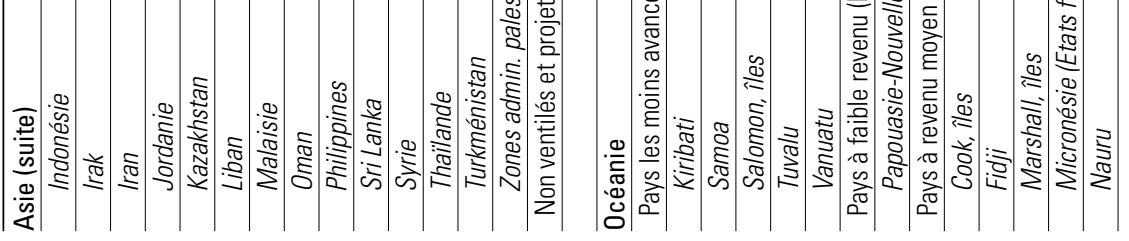




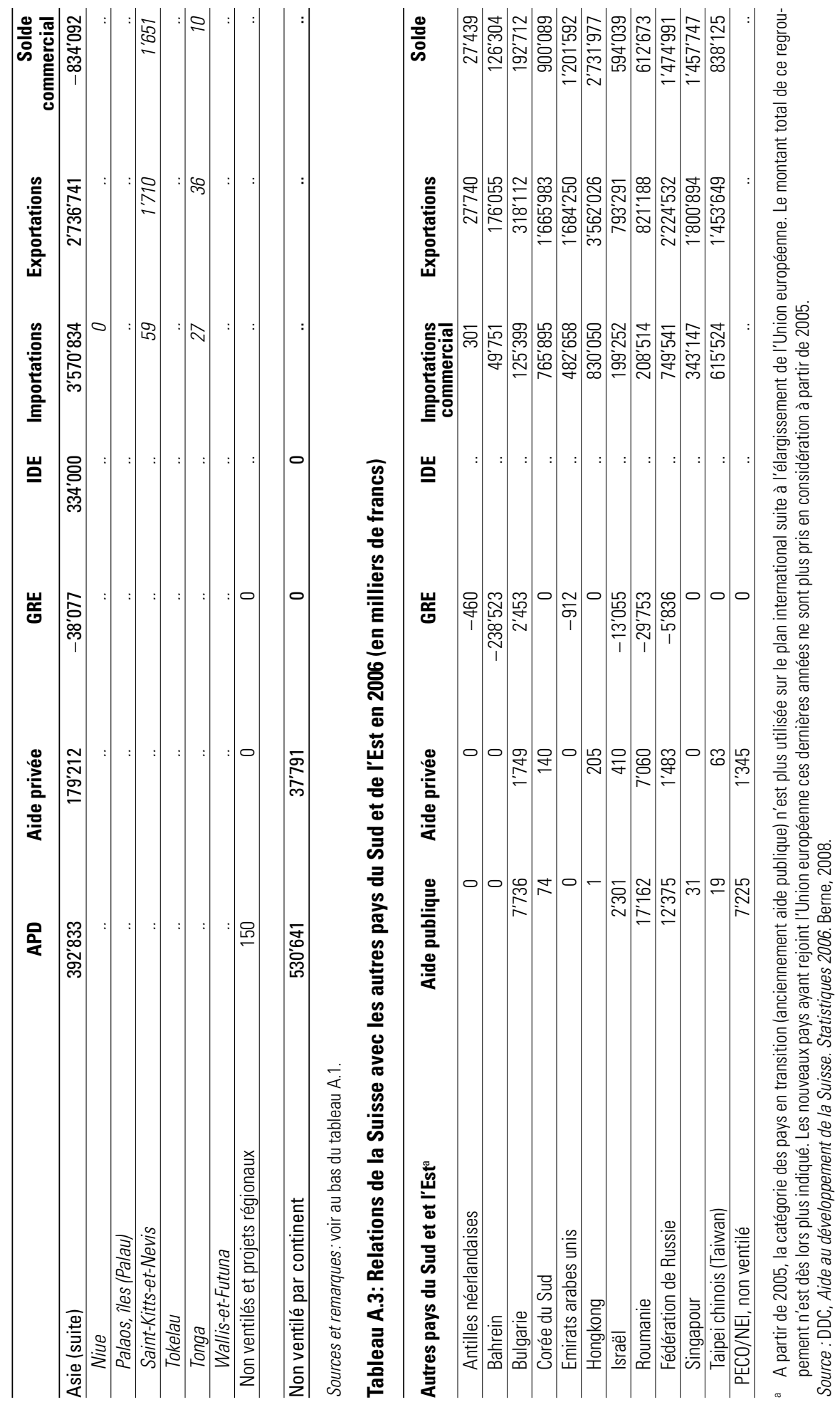

